\title{
CHALLENGES RELATED TO WORKING CONDITIONS EXPERIENCED BY SOCIAL WORKERS PRACTISING IN RURAL AREAS
}

\section{Nicky Alpaslan, Rinie Schenck}

\section{INTRODUCTION, PROBLEM FORMULATION AND MOTIVATION FOR THE STUDY}

In an exploratory study undertaken by Schenck in 2002 focusing on the problems experienced by social workers in rural communities (Schenck, 2003, 2004:165) in five provinces in South Africa, the 45 rural social workers ${ }^{1}$ interviewed articulated the following as difficulties experienced in relation to their working conditions while engaging in social work in rural areas:

- no resources and infrastructure;

- community members' lack of understanding of the role of social workers, and social workers being used as "dustbins" for unresolved problems in the community;

- having to travel long distances to render social work services to clients;

- lack of support from supervisors and the organisation;

- clients' cultural/traditional customs and practices hampering social work service delivery;

- lack of confidentiality.

In corroborating the findings of Schenck's research (2004) and in reporting on the nature of the working conditions of social workers, Margaret Kusambiza, Director of the Eastern Cape NGO Coalition quoted in Chibba (2011) stated that "the profession is stressful", its "workers remain underpaid ... Many are forced to leave the country because of poor working conditions and low salaries. We don't have enough facilities for social workers." Kruger (2008:44) in the "Draft Discussion on Rural Recruitment and Retention of Social Workers: Consulting the Field" concludes that one of the major reasons why it is such a challenge to retain social work practitioners in rural and remote parts of our country was "poor working conditions". The Minister of Social Development, Bathabile Dlamini, quoted by Ngomane in The Citizen (2010:4) echoes these statements when she mentions that the movement of social workers to other sectors and other countries is because of better working conditions and lucrative salary packages there.

In view of the references to the "poor working conditions" of social workers (Kusambisa in Chibba, 2011), which make it a challenge to retain social workers in rural areas (Kruger, 2008:44), and the exodus of social workers from the profession in search of "better working conditions" (Dlamini in Ngomane, 2010:4), the researchers' decided to embark on a research project with the aim of revisiting and exploring the working condition-related challenges experienced by social workers practising in rural areas.

\section{RESEARCH APPROACH AND METHODOLOGY}

A qualitative research approach was followed since, through the utilisation of research methods such as in-depth interviews, focus group discussions and participant observation, it afforded the researchers an opportunity to revisit and explore the issue from the perspectives and experiences of the participants themselves (Hennink, Hutter \& Bailey, 2011:8). This approach

\footnotetext{
${ }^{1}$ Baker (in Sidell, Boughton, Hull, Ertz, Seeley \& Wieder, 2006:26) defines "rural social workers" as those "whose predominant clientele and practice activities are in sparsely populated regions".
} 
afforded the participants, as self-knowing subjects, the opportunity to speak authoritatively about their experiences while practising social work in rural areas. The approach enabled the researchers to provide vivid textual descriptions of the "human" side of the issue (Mack, Woodsong, MacQueen, Guest \& Namey, 2005:1). Wheeldon and Faubert (2009:69) such an approach and point to the fact that qualitative research provides opportunities for the exploration and interpretation of participants' social worlds by focusing on their experiences and histories. These activities of first exploring and then providing a descriptive interpretation, according to Funk, Stajduhar, Toye, Aoun, Grande and Todd (2010:594), enable qualitative researchers to generate "detailed, nuanced, 'grounded' and contextualised understandings of individuals' experiences".

Within the qualitative approach, and in view of the fact that the functions of qualitative researchers have been referred to as "explorative", descriptive" and "contextual" in that (with reference to the latter in particular) it concerns itself with identifying what exists in the social world and the way in manifests itself (Ritchie \& Lewis, 2005:27-28), the researchers employed an explorative, descriptive and contextual research design or strategy of inquiry.

An explorative research design was incorporated as part of the strategy of inquiry in revisiting the challenges experienced by social workers in rural areas. Neuman (2000:21) explains that explorative research is normally undertaken when one aims to explore a topic or an issue. For the purpose of describing that which was explored, a descriptive research design was employed. Descriptive studies are studies that aim to describe phenomena without providing causal explanations of the phenomena (Terre Blanche, Durrheim \& Painter, 2006:558). The explorative and descriptive research designs matched the qualitative approach, as Krieg Mayer (2001:93) state that the former entail an "exploratory, descriptive method". Struwig and Stead (2001:8) indicate that contextualising research emphasises both the macro and the micro contexts in which the individual finds himself or herself, and the way that these contexts interact with each other. The contextual research design was incorporated as part of the strategy of inquiry for this research project as the researchers aimed to explore and describe specifically the working condition-related challenges experienced within the context of social workers practising social work in rural areas.

Purposive sampling, as a non-probability sampling technique, was employed. In explaining the nature of purposive sampling, Abrams (2010:538) writes that "the researcher exercises his or her judgement about who will provide the best perspective on the phenomenon of interest, and then intentionally invites those specific perspectives into the study". Seven fourth-level student social workers were recruited and tasked with the responsibility of procuring a sample, collecting, and analysing the data. To obtain participants for inclusion in the sample, the fieldworkers approached the directors, programme managers and supervisors of governmental and non-governmental organisations rendering social work services in rural areas and informed them about the proposed research project with the view to seeking their permission to conduct the research project amongst the rural social workers from their organisations. Where permission was granted, the directors, programme managers and supervisors concerned were requested to bring this research endeavour to the social workers' attention. They were also requested to put the fieldworkers in touch with possible participants who indicated an eagerness to participate in this research project and who met the criteria for inclusion indicated below.

In view of the fact that "sample size" in qualitative sampling is rarely determined at the outset of the study (Abrams, 2010:539), the researchers and fieldworkers were led by the principle of "saturation of data" to determine the sample size. The field workers collected data from the 
participants until the information obtained became repetitive (Fossey, Harvey, McDermott \& Davidson, 2002:72; Donalek \& Soldwisch, 2004:356). After 32 in-depth interviews were conducted by the field workers and the digital recordings of these interviews were transcribed word-for-word by the fieldworkers, the first author read through all the transcripts and concluded that the data had reached a point of saturation and that the process of data collection could be concluded. Only participants who met the following criteria were included in the study:

- social workers in the employ of governmental and non-governmental organisations practising social work in rural ${ }^{2}$ areas;

- participants who were available and willing to participate in the study, in that they were fully aware of what the study entailed, and participated of their own free will.

Within the context of qualitative studies, the most commonly used methods of data collection are different types of interview and focus group discussions aiming to explore participants' perceptions and experiences in relation to the research topic (Hartley \& Muhit, 2003:106). In this research, one field worker, apart from conducting a number of in-depth interviews, conducted one focus group discussion (with four participants), while the rest of the fieldworkers employed in-depth face-to-face interviews involving one interviewer and one participant for the purpose of data collection. For a focus group discussion a researcher and several participants meet to discuss a given research topic (Mack et al., 2005:51). With reference to in-depth interviews, Mack et al. (2005:29) write: "The in-depth interview is a technique designed to elicit a vivid picture of the participant's perspective on the research topic. During in-depth interviews, the person being interviewed is considered the 'expert' and the interviewer is considered the "student" (Milena, Dainora \& Alin, 2008:1279). In-depth interviews afford participants the opportunity to share personal feelings, perceptions and opinions, and to talk about their experiences. It allows the researcher to gain an insight into how people interpret and order the world (Milena et al., 2008:1279). The in-depth interviews conducted by the fieldworkers were structured according to questions specifically formulated for the purpose of obtaining biographical data about the participants, while there were a limited number of questions pertaining to the topic under investigation specifically; these questions were contained in an interview guide. ${ }^{3}$ The questions formulated on the research topic specifically focused on:

- the participants' motivations for being engaged in rural social work;

- their working conditions in terms of what they like and dislike;

- the challenges experienced in relation to practising social work in a rural area;

- suggestions on how the challenges experienced could be addressed.

\footnotetext{
2 To define "rural" is difficult and its meaning varies from country to country and there is no consensus in the literature about the description of "rurality". For the purpose of this study we accept Mayer's (2001) and Rankin's (1992) descriptions stating that "rural" refers to the areas outside the bigger metropolitan centres and towns in South Africa. Rural areas are characterised by a low population density and a general absence of built-up areas (Schenck, 2003:8).

${ }^{3}$ Holloway and Wheeler (1998:55) and Kvale (1996:174) note that to direct and focus the interview and to cover all the aspects and issues related to the topic under investigation, "an interview guide" is used and not a schedule or questionnaire, as in quantitative research.
} 
With the consent of the participants, all the interviews were digitally recorded. On completion of the data-collection process, the fieldworkers transcribed the recordings word-for-word. Subsequently the process of data analysis commenced as an independent venture between the fieldworkers and the first author. Creswell (1994:153) states that the researcher is involved in several activities during the phase of analysing the qualitative data generated (i.e. the researcher transcribes the interviews, sorts the data into categories, formats the data into a coherent story or picture, and writes the qualitative text.) The fieldworkers and the researcher employed the eight steps provided by Tesch (in Creswell, 2009:186) to analyse the data systematically by segmenting it into words or categories that subsequently formed the basis of the emerging story or picture.

For the purpose of ensuring the trustworthiness of this research project undertaken from a qualitative approach, the researchers employed Guba's model of trustworthiness as explained in a user-friendly way in Krefting (1991:215-222) and Shenton (2004:63-75). It identifies four criteria and strategies for ensuring and establishing trustworthiness, which are therefore used to assess the qualitative research process undertaken.

- The first criterion used to ensure trustworthiness relates to "credibility" or "truth-value" (Krefting, 1991:216). Credibility deals with the question: "How congruent are the findings with reality?" (Shenton, 2004:64). In ensuring that the researchers had accurately recorded the phenomenon under investigation, the following strategies were employed:

- triangulation - that is, triangulation of data sources [i.e. interviewing multiple participants], and the triangulation of different investigators [i.e. the fieldworkers and the researchers] involved in this research project);

- peer examination (i.e. regular discussion and consultations between the fieldworkers and the first author);

- the interviewing techniques used by the fieldworkers;

- the researchers overseeing the fieldwork process regarding background, qualifications and experience; and

- the examination of the previous research findings to assess the degree to which the project's results are congruent with the former (Shenton, 2004:65-69).

- The second criterion, "transferability", relates to "external validity" and is "concerned with the extent to which the findings of one study can be applied to other situations" (i.e. the applicability of the research findings) (Merriam in Shenton, 2004:69). In view of the fact that the researcher knows only the "sending context", he or she cannot make any transferability inferences (Lincoln \& Guba in Shenton, 2004:70), Mary Rodwell (in Ungar, 2003:95), writing from the perspective of a constructivist qualitative social work researcher, states: "If the findings transfer, it is the responsibility of the reader of the inquiry report to make that determination, since it is only the reader, not the inquirer, who can be familiar with the time and context in which transfer of the findings might be possible". Lincoln and Guba (in Ungar, 2003:95) point out that the researcher has the responsibility to provide a "thick description" so as to enable someone interested to conclude whether transfer can be contemplated as a possibility. For this reason "dense" descriptions of the research methodology and findings were provided.

- The third criterion of Guba's model (in Krefting, 1991:215-222) is termed "consistency", which is concerned with the extent to which the replication of the study in a similar context 
or with similar informants will produce the same results. Dependability was the strategy used to ensure consistency. The actions that were taken to ensure dependability in this study included:

- peer examination of the research methodology and its implementation;

- triangulation of data sources and investigators;

- a dense description of the research methodology;

- independent coding (i.e. the fieldworkers and the first author independently analysed the whole data set; and

- the implementation of a code-recode procedure) (Krefting, 1991:216-217).

- Confirmability is the strategy employed to achieve neutrality and it is concerned with whether the study's findings are free from bias. It requires the inclusion of steps to ensure as far as possible that the findings reported are the result of the perceptions and experiences of the participants and not the characteristics and preferences of the researchers (Shenton, 2004:72). In this study triangulation (as explained above) was employed to achieve confirmability (Krefting, 1991:221-222).

Certain ethical aspects were adhered to by the researchers and the fieldworkers involved in this research project. Research ethics can be viewed as standards that guide the researchers' and fieldworkers' decisions and behaviour and in particular how they interact with the participants involved in the study and how they deal with the information shared by them in confidence (Flew in Greenberg \& Baron, 2008:736; Mack et al., 2005:8). As was stated earlier, the fieldworkers obtained permission from directors, programme managers and supervisors in the employ of governmental and non-governmental organisations to conduct the research and for rural social workers to be available to participate in this study. Written consent testifying to the fact that the participants were comprehensively informed about the aim and value of the study, what their participation entailed and their rights were, was obtained from every participant prior to each interview. Participation in the study was voluntary with the agreement that participants' identities would be protected. In order to protect their identities, the fieldworkers replaced participants' identifying particulars on transcripts, notes and digital recordings with pseudonyms. In order to safeguard participants' information, the fieldworkers and the researchers kept the recording, notes and transcripts of the interviews in locked cupboards and undertook to destroy the documents once the research paper was published.

\section{DISCUSSION OF FINDINGS}

The research findings are based on the analysis of the 32 in-depth interviews conducted with a sample of social workers practising social work in rural areas and a consensus discussion between the researchers on the data analysed independently by each of the field workers and the first author.

The discussion on the research findings is presented in two sections, namely:

- an account of the geographical areas where the study was conducted and the biographical profile of the participants;

- a discussion of the themes and sub-themes that emerged from the process of data analysis and the consensus discussion, supported by narratives from the transcribed interviews complemented by a literature control. 


\section{GEOGRAPHICAL AREAS WHERE THE STUDY WAS CONDUCTED AND BIOGRAPHICAL PROFILE OF PARTICIPANTS}

The study was conducted in four provinces, namely:

- Mpumalanga (specifically in the rural and farm areas surrounding Nigel, Secunda, Evander and the Mkhondo Municipal Districts);

- North West (in the rural areas of Bloemhof and Christiana);

- Eastern Cape (Cacadu District in Humansdorp and Hankey);

- Western Cape (The Theewaterskloof District)

The reason for only using these provinces is that the seven fourth-level student social workers who did the fieldwork originated from these provinces.

Nineteen out of the 32 participants originated from the province of Mpumalanga. ${ }^{4}$ Seventeen participants from this sample were female and two male. Their ages ranged from 25 to 65 years. Their race distribution was as follows: 11 were black, one Indian and seven white. The number of years of practice experience of this sample ranged from five months to 35 years.

The sample from the North West Province was comprised of five participants with one being a black male, 27 years old with five years practice experience as a social worker. The other 4 participants who made up the sample in this province were female, with three being white and one black. Their ages ranged from 28 to 53 years and their social work practice experience ranged from seven to 32 years.

The sample of participants from the Eastern Cape was comprised of four black females, whose ages ranged from 25 to 45 years. Their social work practice experience ranged from 15 months to 25 years.

The Western Cape sample was comprised of one male social worker (white) and three female social workers. Two of the latter were white and one coloured. Their ages ranged from 40 to 55 years and the number of years practising as social workers from 14 to 25 years.

The biographical data underscore the tendency of social work being a "female-orientated profession" (Christie \& Kruk, 1998:25).

\section{DISCUSSION OF THE THEMES AND SUB-THEMES AND A LITERATURE CONTROL}

From the process of data analysis the following three major themes emerged:

- participants' motivations for practising social work in rural areas;

- challenges encountered while practising social work in rural areas and dislikes related to this.

These themes and their related sub-themes are described more fully below.

\section{Theme 1: Participants' motivations for practising social work in rural areas}

From the information shared by the participants, it became clear that a variety of factors served as push-and-pull factors or motivations for practising as social workers in rural areas. Some of

\footnotetext{
${ }^{4}$ The over-representation of the participants from this province was due to the fact that four of the fieldworkers originated from Mpumalanga and it was convenient for them to sample participants from the province in which they were located.
} 
them had to migrate to these areas because of their spouses' career changes, the fact that they got married to a spouse who stayed in a rural area, because of their own financial circumstances, and because they originated from the rural areas and they were of the opinion that this is where the real need for social work services lies. The aspects characteristic of the rural area and the people residing in rural areas (i.e. the fact that the rural area seems to be safer and the work pace calmer, and the clients are more responsive and appreciative of social workers and the services they rendered) also served as motivation for moving to and practising rural social work. The latter aspect was largely articulated under what the participants "liked" about practising social work in a rural area. In support of this, the following storylines are provided:

"My husband was transferred here and I applied to be transferred".

"I was transferred here and because I am a single parent I do not want to forfeit my pension and housing privileges. Therefore I accepted the transfer which was coupled with an increase of status and salary".

"It has always been my husband's dream to be a farmer and after his father died eight years ago, he [referring to the father-in-law] owned a farm which was situated just 5 $\mathrm{km}$ out of town. I resigned from my post and after two years of being a housewife I started to work for this NPO organisation” (Schenck, 2003:15).

"I got married to a local farmer".

"I had an opportunity to witness all the difficulties that people encounter [i.e. this participant grew up in a rural area]. I developed an interest in helping people who live in such rural areas".

"I decided I can work here because I don't want to work in a big place. I want it to be like home [i.e. like a rural area she originates from]".

"It is safer rural ... our offices are comfortable... the area is nice and clean".

"The pace is a lot calmer, and the work is more personal in the sense that the people are warmer... I like the peace and calmness here".

"People in the areas still live 'Ubuntu'”.

"I think small towns and rural areas have more of a community sort of relationshippeople care about one another ... neighbours worry about each other ... they will phone the social worker and say 'This lady is not taking care of the child' or 'This child is running around here outside late at night",."

"The people are so excited that you really were willing to come to them. ... They invite me into their house. I am so important for them ... if we leave, they want to give their cow's milk - I must take also from that milk... It is 'wow' - 'it is amazing' that this lady, does all this trouble to come and see us. The children also - they can't believe that people in the year 2010 still are willing to do things for them”.

"For everything you do they are so thankful ... they are still hospitable... trustworthy ... they have some manners. They know their neighbours ... and ... the eagerness, some of them are so willing to learn, so willing to get involved ... and to start with nothing". 
"I like rural areas because I think people are different and they need more services ... especially community work in rural areas".

When comparing the motivations cited above for practising social work in rural areas with the findings of Schenck (2003:17-18) in this regard, many similarities were found. The findings of this study also corroborate the findings of Sidell et al. (2006:32) in which a sample of 117 social workers in one of the rural counties of Pennsylvania mentioned that family ties were one of the reasons for living in a rural setting. Furthermore, and in support of the statements made, the participants in the research by Sidell et al. referred to the pleasantness of the rural surroundings and lifestyle (i.e. "quiet", "peacefulness"); the fact that this was the only place of employ, and a spouse's employment situation as factors pushing them to relocate to a rural area. Having family in the rural areas, growing up in a particular rural area and the "sense of community" and positive feelings about neighbours were also highlighted in the research by Sidell et al. (2006:32) as motivations for staying and practising social work in the rural areas. Brown and Green (2009:68), in underscoring some of the storylines quoted, state that a sense of belonging and contributing to a community by making a difference in real and observable ways over time, and the rural lifestyle experiences are some of the positives related to practising social work in rural areas.

\section{Theme: Challenges currently encountered while practising social work in rural areas and dislikes related to it}

This theme originated from the responses of the participants to the following questions: (1) What do you dislike about rural social work? and (2) What are the challenges experienced while practising social work in rural areas? The information provided by the participants in response to these questions led to the decision to sub-divide this theme into three sub-themes and one unique theme to be introduced and presented in the discussion below.

\section{Sub-theme: Lack of resources as challenge experienced while practising social work in rural areas}

This challenge of lack of resources was referred to by all the participants. Specific mention was made of the lack of offices and office space, a lack of office equipment, a shortage of vehicles and/or vehicles not suitable for travelling on the roads in rural areas. Participants expressed themselves as follows in this regard:

"I render my services at the drop-in centre ... We [referring to the social worker in the area] don't have places where we can render social work services... like we have to go ... to the police stations, drop-in centre and clinics... we only have a room. Then you come with your files and diaries and take the in-takes. Nothing else. No photocopies, not even a phone, even if you want to phone the client, there is no phone".

"Our offices [i.e. referring to the Department's offices in the rural areas] are not up to standard like the offices in the cities. They are small with six to eight people in each office. Computers are not enough. We share them and we also share telephone lines. I think it is destructive because it is difficult to concentrate in the office because we are many. There are too many distractions, people walking through. You hear other people speaking, talking on phones, colleagues chatting to one another, the supervisor coming to speak to somebody. That disrupts everybody. It is also worse when they are playing radios. Some staffs work with radios on. Also the fact that you are dealing with confidential nature of things. You do not have confidentiality in a small office. You have to talk very softly. It's not good to work in rural areas". 
"My computer has been broken for the last five days and it is the second time in three months... This is jolly frustrating".

"Most of the time, there is one vehicle, whereas you are three or four social workers depending on that vehicle ... services will not be delivered the way they are supposed to be delivered".

"Vehicles offered by the Government are not suitable to go there in those areas. Some areas are on the mountains and you are using for example a Golf or a Mazda to go down whereas you are supposed to use a bakkie [a van/pickup]".

"The infrastructure is bad, the roads are disastrous... sometimes there is not even a road so you have to park your car very far and walk where you have to be".

"The area you cover is much broader and this means you have to travel greater distances, so this is equal to more time on the road and less time to work".

"You drink water with cows and donkeys ... there are also no toilets".

The challenges articulated above correspond with Schenck's research findings (2003, 2004). The participants in her study (Schenck, 2003:55, 57-61; 2004:165-166), especially the rural social workers in the employ of the Provincial Departments of Social Development, felt the burden of offices and office spaces being in appalling condition (i.e. offices were inaccessible, office space limited and social workers had to share offices, even with other professionals, no facilities, such as waiting areas, toilets and electricity) and a large number of the participants in her study had no telephones, computers or even fax machines. Schenck's participants also mentioned the shortage of vehicles, vehicles not suitable for travelling on gravel roads, causing social workers to travel on foot to reach clients in mountainous areas, and the distances to reach clients as a challenge. The participants in the study by Sidell et al. (2006:32) (i.e. social workers in one of the rural Pennsylvania counties) mentioned "limited resources" (ForceEmery Mackie, 2007:115), a "lack of services/resources/funding" and a "lack of transportation" as the primary challenges faced by rural social workers. Pugh (in Force-Emery Mackie, 2007:117) states that the challenges experienced by rural social workers result in inequities in service provision and this complicates service delivery and access to services.

\section{Sub-theme: Lack of funds for implementation of projects in rural areas as a challenge experienced}

In accentuating this sub-theme and latching on to the reference made by Sidell et al. (2006:32) that "lack of funding" is one of the primary challenges faced by social workers in rural areas the following storylines are provided:

"There seems to be not enough funds for many projects. Many people in rural areas are not working and they therefore want to be engaged in projects most of them ... We're expected to implement programmes but there is no financial support. How then are we expected to implement those programmes?"

“... but now with our budget cuts we cannot do all the campaigns”.

"We try our best [to fundraise] - we do... Fundraising is a big problem... it's time consuming ... we do not get sponsors... there are no sponsors ... it's a small town...it [referring to the town] does not have big industries to help". 


\section{Sub-theme: Challenges experienced in relation to the nature of the work and the clientele serviced while practising social work in rural areas}

This sub-theme is presented under various categories below.

\section{- Challenges experienced in terms of high caseloads, multiple role responsibilities, shortage of staff}

The participants referred to high caseloads, a shortage of staff and multiple role responsibilities as some of the challenges with which they are confronted while practising social work in rural areas. They expressed this along the following lines:

"We have high caseloads here in the rural areas. [When] ... social workers leave rural areas to go and work [in] the cities their work is distributed amongst us. Moreover, the Government does not employ any social workers to replace the ones who resigned. The intake rises now that the people in the rural areas become aware of grants."

"We have got a lot of clients to see and we have to attend to other programmes such as Poverty Alleviation, Drug Master Plan. Ifeel our caseloads are too high."

"Lack of staff resources, especially social workers."

According to the participants the shortages of social workers are because of "salaries [being] inadequate", "the salary does not really make you feel as if it is worth it and you have to try and do a lot of work in a time limit with very limited resources", "a lot of our black colleagues will come and work at $X$ [An NGO]... We put a lot of training into them and showing them how to work, and as soon as they have the knowledge they go to the Department, because they get more money there ... There is a housing allowance ... they get a car. The NGOs are the training schools in the rural areas... and we do it [referring to the training] with our own money not theirs [referring to the Department]". Smith, the Registrar of the South African Council for Social Service Professions, (quoted by Oliphant in The City Press, 2009:12) confirms the fact that NGOs are losing social workers to the government and states that "while government is making progress to stop the poaching of social workers by overseas countries, something needed to be done to stop government from taking non-governmental organisations' staff."

"These days the profession frustrates me immensely, we must get to the people and focus on them, but $90 \%$ of our work consists of admin ... we never get to the people”.

"There are a lot of administrative responsibilities, which at times prevents me from doing other social work functions. There is just no time to finish work. Sometimes I take work home."

"We are constantly under pressure here because there are too many cases, more especially those priorities of the Department like HIV, orphans and vulnerable children."

"We constantly get pressure from clients to finalise their cases. They are not aware that we depend on dates given by magistrates. People do not understand when they have to wait for ... their cases are finalised."

“Workers are expected to be a 'jack of all trades', you don't get anything done properly. Things like therapy that is important, but take a long time, seldom or never gets attended to." 
In response to the multiple role responsibilities of rural social workers (i.e. being the "jack of all trades"), Lohmann and Lohmann (2005:6) state that "practice realities in many rural areas are as such that the social worker will be called upon to handle a wide range of tasks and carry diverse helping roles".

The issue of high caseloads was mentioned not only by the participants in this and Schenck's study (2004:162-163), but is characteristic of the whole South African landscape. Govender, writing in the Sunday Times (28 October 2007:13), reports the views of the Public Servants Association, which represents government social workers, that social workers have to cope with caseloads ranging from 600 to 3000 in extreme cases, while their British counterparts carry a caseload of between 13 to 20 cases. In this newspaper article the shortage of social workers in South Africa is estimated at 50 000. To explain the shortage of social workers in rural areas (mentioned in the quotations above) and the challenges to recruit and retain social workers for rural practice, Force-Emery Mackie (2007:114) put forward the following reasons: geographic isolation, workplace issues (i.e. poor organisational conditions, lack of professional support) and occupational stress. Confirming the references to "poor salaries" and the discrepancies in the salaries paid by the Department and the NGOs, Cull refers in the EP Herald (2006:9) to PE Childline's Anni Rossouw, who informed the Bisho legislature's finance committee that "entry-level social workers in the NGO sector were paid little more than half of what their counterparts in the Eastern Cape Department of Social Development earned and it was 'degrading' for social workers in the NGO sector to be 'treated as cheap labour'". Versluis, writing in Die Volksblad (2005:7) echoes a similar sentiment when referring to Oosthuizen, leader of the Freedom Front Plus in the Free State, who mentions that social workers with a four-year university qualification entering social work practice earn less than a cleaner in the Free State legislature. This article also mentions the disparities in the remuneration of social workers employed by the state and that of the NGOs.

This state of affairs of high caseloads and shortage of social workers (specifically in the rural areas) leads to a situation where social workers only practise one method of social work or engage in one type of service being rendered. The following storylines are provided in confirmation of this.

"You do not have time to combine individual work with developmental work because it doesn't work like that anymore. ... In the position where I am in now, [I] can't do developmental work because I haven't got the time, and I'm busy with children's courts, statutory work all the time."

"I only do casework ... I would like to do other things but there is no time for me."

"We never have enough social workers, which is why I only do statutory work."

This routine or repetitive work tires and frustrates the participants, as was poignantly articulated by two of them:

"We as social workers working in rural areas are so tired of doing the same thing over and over again. There is no space to move anywhere ... People do foster care all the time and end up not doing their best because they feel they have been doing this routine work."

"I think people are fed up doing the same thing again and again. People want to do other things but the chances to do something else are so limited." 
These comments coupled with the high caseloads and shortage of staff being part of rural social workers' day-to-day practice-related challenges and realities result in what Ross and Altmaier (1994:37) refer to as a "quantitative role overload". The latter boils down to a situation where one does not have the luxury of enough time to complete all the work that is required in one's job. The following statements testify to this "quantitative role overload":

"Life here is very hectic and full of expectations. There is a lot of pressure on you ... I am not even able to cope with all the deadlines because of all the demands placed on me."

"My programme is so full, there is just no time to even chat to my colleagues or even take lunch. I ... work through my tea breaks and lunch time to try catch up ... My administration tasks are just piling up... I never have time to switch off. I just carry on."

\section{- Client-related challenges experienced while practising social work in rural areas}

Apart from the challenges referred to under the previous category, the participants also mentioned client-related challenges such as: clients' levels of illiteracy, clients' ignorance about social services rendered by the government, clients' not having identity documents in order to apply for grants, their dependency on social grants, the levels of poverty, and clients' lack of motivation, action and cooperation (Kruger, 2008:34; Schenck, 2004:159, 161). Furthermore, customary cultural practices and differences, gender and age differences, and language barriers were also mentioned as client-related challenges. The following statements underscore these client-related challenges:

"Other people in the community are illiterate, they are not well educated or they never saw a school. They do have problems but they do not know whether they are coming to the right door."

"A lot of people don't have documents. They work on the plaas. So if the older people don't have documents you find that the whole generation has no documents. If you ask why they don't have IDs you see that they are just ignorant - they don't see the need."

"Parents don't have birth certificates, now that kids don't have, so to place those children - you can't. The court requires that you have an ID and the Department doesn't want to do late registrations. Home Affairs Officials will treat them with disrespect or discrimination and chase them away. We can't help them with IDs ... it is not our field."

"The conditions of families who receive a state grant do not ... improve; instead, they are becoming more dependent ... Some members from families who receive grants are begging on the street."

"Clients don't come in [i.e. to see the social worker]... Sometimes the clients cooperate - [especially] with statutory cases and if you tell them it's going to affect the grant, then they will be there ... They will have excuses other times, but if it's about the grant they will be there."

"Rural people do not have information about the services rendered by government."

"You will deliver the reports or phone your client that he or she must visit the office. She will not come and make an excuse, saying: No, I didn't have the money for transport so that I can visit the office." 
"You get there [where the clients stay] and you find that they no longer stay there. They never informed you that they are moving."

"If the phone number changed, then you have a big problem ... there is some of the clients that don't have a phone ... or if they have cell phones ... they have no signal there."

"When they talk about 'the poorest of the poor', you understand. People are hungry... we've a recession and the people are unemployed and it is not easy."

"There is very little income in most families and people survive on grants ... People lie so that they can access services. Even when they do not qualify for services."

"We have very little resources here. Poverty is our biggest challenge."

With reference to customary cultural practices and differences as challenges experienced by some of the participants in relation the clients they service, the following supporting storylines:

"I do think in some instances they'll prefer someone from the black community as they will understand the goings on in the community."

"Well, I grew up in a very small family ... we do not really have any traditions, we are quite modern. When I spoke to my client whose daughter just died and I wanted to take back her daughter's children [bringing them to the grandmother], she said she cannot [take the children as yet] because she is still in mourning and she has to complete all sorts of rituals before she can take the children."

"[You are] restricted by Isibonda or by the community leader. You can't go beyond a certain point [of offering help] although problems are still arising from the community."

"In a rural area people have certain customs. You can't just come in here and render a service. It does not work like that. You have to go there and get the consent of the community leaders to render the services in a rural area."

"The other thing is that leadership structures in a rural area wouldn't be as clear as in urban areas and that makes things difficult because you are not sure who to contact on some of the things, there is that complexity in terms of leadership structures and the hierarchy in rural areas. You end up not knowing who has precedence over whom and that makes your operation very difficult as a social worker."

In confirmation of the last three statements provided above, the custom of seeking permission from community leaders and structures to render services to rural communities also surfaced as a theme in Schenck's 2002 study (2004:166-167). Like the participants in this study, the participants in her study experienced this as a challenge and source of frustration, especially in the predominantly black rural communities. In defence of these communities, Molefe (1996) postulates that in rural areas people feel obliged to follow customs and traditions, and cautions that the way in which rural communities go about their daily lives should be recognised and they cannot be changed radically without disrupting people's lives.

In underscoring the reference to gender and age differences and language barriers as challenges experienced by the participants in relation to the clients they service, the following quotations:

"I am still a young guy ... they think I cannot help them." 
"You will also see someone undermining you because you are young and you are a woman."

"I am 24, 25 ... when you arrange marriage counselling ... they look at you and then some of them would even ask if you are married."

“... because more especially our clients are older people, it goes with the age group. It's like they see you differently - they don't open up easily."

"It is very dangerous for a man, rurally specifically, to work with women or girls, female clients that are victims of sexual crimes [as the community within which he works is often small and close-knit which may allow for false interpretations and rumours to develop quickly].'

"I often struggle with non-Nguni-speaking people where often translators need to be sourced or such clients need to be referred to other social workers."

"Sometimes you get to work with a client who only speaks Xhosa. Sometimes you don't understand the language."

"Working with clients from a different culture is challenging especially if it is children and they can only speak one language."

Sub-theme: Lack of cooperation and courtesy amongst NGOs, government, state departments and service providers, as well as a lack of specialised services and resources in rural areas as an experienced challenge

In substantiating this sub-theme the following storylines are provided:

"Lack of cooperation is really bad... [and lack of professional courtesy]... People are too busy; they never get back to you."

"I have to work with the Police but they are so busy and cannot assist me."

"Not enough communication between various State departments and the NGOs."

"There is no hospital ... no psychologists ... SASSA department is only coming twice a week. Home Affairs only once a week. Our magistrates ... they are not here each and every day ... it's like to be on an island."

Sub-theme: Lack of, and fear for, personal safety as a challenge experienced by the participants

In underscoring this sub-theme the following statements by participants are provided:

"You are very much on your own and not always safe."

"There is no security; if somebody wants to attack you they can attack you."

"It is dangerous to be a social worker at X [name of the rural area]."

"Colleagues that are working in KwaZulu-Natal in the rural areas [told] me it is not safe there ... they will tell me that 'we are getting transfers, we don't want to work there anymore'. If you ask them why they will tell you, 'you know that Inquata people? Maybe you want to intervene between the couple, the wife and the husband. Then those people staying in KwaZulu-Natal ... they carry guns and sticks. If maybe you intervened ... during the night they will come ... shoot you, attack you ... because you intervened ... you will suffer the consequences." 
"People get dogs to keep social workers out. I've been bitten by one client's dogs."

"Our safety is a concern ...these days black and white clients are equally aggressive ... you have to be careful ... people are nasty these days ... one of our colleagues was held at gunpoint in his own office ... it's a jungle outside."

The aggression harboured against some of the social workers may be founded in stereotypical views about what they do and the stigma attached to the activity of being a recipient of social work services. This was poignantly stated as follows by a participant:

"We've got one client that was crying. She said, it's humiliating for her and she doesn't want to be associated with the Welfare. She feels that she is going to be traumatised, her family and her child will be traumatised ... Social workers I feel don't have a position in the community, because you are a threat ... the 'moeilikheidmaker'."'

This sub-theme and supporting storylines under discussion are supported in the literature (Green, Gregory \& Mason, 2003:94-105; Green, 2003:215) and in a summarising manner mirrored in the following utterances made by two of the participants in the study by Green et $a l^{5}$ (2003:100): "I feel that living and working in a rural community is full of risks ... the nature of my work is that there are always risks ... People don't understand my work objectives and may seek to [demand] some kind of payback for real or imagined actions that I have taken in my professional capacity" and "My work mostly relates to a client group where violence and harassment is pretty much part of the work ... mostly emotional and mental abuse and verbal harassment. Where there is a threat of physical violence this is far less threatening to me than these other forms of violence which I face on a daily basis."

\section{Sub-theme: Lack of supervision, need for supervisory support and peer support from colleagues whilst practicing rural social work}

The following statements from the transcribed interviews underscore this sub-theme:

"As social workers in rural areas, we feel neglected because of lack of proper supervision."

"I think that the scarcity of supervision in rural areas is caused by the unpleasant working conditions, people do not like to work in rural areas."

"You really need support from your colleagues because at times you get so involved with the case. Discussing it with others will help. However, there is no time for this. People are very busy with very heavy workloads."

"Supervision with work and administrative matters is fine, but emotional issues get left behind."

"There is always this long queue to see the supervisor."

The references above, specifically to the lack of supervision, corroborate a finding in Mayer's study (2001:96), where a lack of good supervision was highlighted as one of the challenges experienced by the participants. For most of them it was either not provided or it focused mainly on maintaining agency standards rather than the development of knowledge and skills. This lack of supervision and the reality that some rural social workers have no immediate

${ }^{5}$ This study was conducted in rural Victoria, Australia. 
colleagues available with whom to discuss practice matters and to bounce off decisions that have to be taken in respect of clients, may cause rural social workers to engage with people outside of the work situations about these matters. This state of affairs might lead to a breach of confidentiality (Pugh, 2007:1415-1416). In view of the need for supervision, Green (2003:215) recommends that "Rural social workers must have agency support, adequate supervision and proper training to ensure they can practice competently, professionally and securely in rural and remote locations" (Green et al., 2003:101).

\section{CONCLUSIONS, RECOMMENDATIONS AND AN AGENDA FOR FURTHER AND FUTURE RESEARCH}

Based on the findings emerging from this research project which aimed to revisit and explore the working condition-related challenges experienced by social workers practising in rural areas, the researcher arrived the following conclusions:

- The working condition-related challenges experienced by social workers practising in rural areas are mainly related to context, service organisation and client-related issues.

- When reading the findings of this research in conjunction with the findings of Schenck's research $(2003,2004)$ in which the problems the rural social workers experienced were articulated, it appears conditions remain unchanged. The researchers came to the conclusion that the working condition-related challenges expressed by the participants in this study (i.e. high caseloads, poor salaries, lack of resources and infrastructure, the vast area to service, community members' lack of understanding of the role of social workers, the lack of support from supervisors and the organisation, and clients' cultural/traditional customs and practices hampering social work service delivery) are the same as those problems that were experienced by the rural social workers in Schenck's study $(2003,2004)$.

The fact that the situation regarding working condition-related challenges and problems experienced by social workers in rural areas seems to have remained unchanged is a matter of great concern, especially in view of the fact that a recruitment and retention strategy was formulated by the Department of Social Development in 2004, which attempted inter alia to offer incentives to work in rural areas and for better salaries (Dlamini in Tshisela, 2010:4).

This current state of affairs calls for a debate involving the entire welfare sector to ascertain what maintains the status quo in relation to the working condition-related challenges and problems experienced by social workers practising in rural areas, what has been done thus far to address these challenges, and what individual and collective actions must be launched in an attempt to address the identified challenges.

In order to prepare social workers entering into social work practice in rural areas for the working condition-related challenges in such areas, the researchers want to note the following suggestions and recommendations that were put forward by the participants.

- Universities must sensitise students more in terms of social work in rural areas as students entering practice are ill-prepared for practising social work in rural areas (i.e. "We did a lot of theory but I did not really know what it 'meant' until I started to work ... You got the knowledge but they did not tell you what you could expect in rural areas." "Students should be trained for the statutory field of social work as well and not just focus on therapy.")

- Social service organisations in rural areas must orientate social workers about rural social work. Turbett $(2009: 513,514)$ concurs and states: "Social workers entering remote rural communities require induction [at their places of employ]... i.e. knowledge of the 
cultural/language context of their client's lives, and not just the usual agency concerns with procedures and policies."

- The discrepancies in salaries and benefits between government-employed and NGOemployed rural social workers need to be addressed.

- In tackle the working condition-related challenges, better cooperation and networking should be established between the National and Provincial Departments of Social Development and NGOs and other service departments in rural areas.

- More regular supervision support should be rendered to rural social workers (i.e. "I think that there in the supervision - it [referring to providing emotional support] should be covered there. Supervision should include all these things [support]. The supervisor should be there ... that will be genuinely good" (Green, 2003:215; Green et al., 2003:101).

- Make social work in rural areas more attractive to prospective rural social workers and social workers currently practising in this area (i.e. a rural allowance, filling of vacancies, lessening of work overload and addressing the feeling of being a "jack of all trades" in favour of opportunities for more specialisation, or providing opportunities for implementing all social work methods, not only case work, or statutory work) (Force-Emery Mackie, 2007:124).

The researchers would also like to propose the following focus areas for future and future research:

- An exploration of the factors maintaining the status quo related to the plight of social workers practising social work in rural areas from rural social workers' perspectives;

- An investigation into the support needs of rural social workers;

- An exploration into the personal safety of rural social workers with reference to their experiences and coping strategies;

- Training social workers for practising in rural areas (compiling an in-service training manual);

- An investigation into the impact of the Recruitment and Retention Strategy of the Department of Social Development on the working conditions of social workers in rural areas.

\section{Acknowledgements}

The researchers would like to thank the following fourth-level student social workers who did the fieldwork, and also assisted with transcribing the digitally recorded interviews and the processes of data analysis: I Edwards, N Ntshangase, R Openshaw, M Rengqe, M Schoeman, J Stapelberg and P M van der Merwe.

\section{BIBLIOGRAPHY}

ABRAMS, L.S. 2010. Sampling 'hard to reach' populations in qualitative research: The case of incarcerated youth. Qualitative Social Work, 9(4):536-550.

BROWN, G. \& GREEN, R. 2009. Inspiring rural practice: Australian and international perspectives. Rural Social Work and Community Practice, 14(1):63-70.

CHIBBA, A. 2011. Better conditions for South African social workers. [Online] Available:

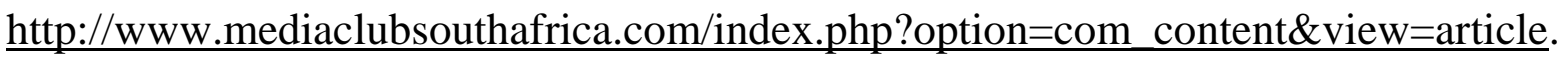

[Accessed: 21/10/2011]. 
CRESWELL, J.W. 2009. Research design: qualitative, quantitative and mixed method approaches $\left(3^{\text {rd }}\right.$ ed. Thousand Oaks, California: Sage Publications.

CHRISTIE, A. \& KRUK, E. 1998. Choosing to become a social worker: motives, incentives, concerns and disincentives. Social Work Education, 17(1):21-33.

CULL, P. 2006. 'Social workers regarded as cheap labour' 'NGO sector being treated unfairly'. The Herald (EP Herald), 15 March 2006:9.

DONALEK, J.G. \& SOLDWISCH, S. 2004. Demystifying nursing research: an introduction to qualitative research methods. Urologic Nursing, 24(4):354, 356.

FORCE-EMERY MACKIE, P. 2007. Understanding the educational and demographic differences between rural and urban social workers. The Journal of Baccalaureate Social Work, 12(2):114-128.

FOSSEY, E., HARVEY, C., McDERMOTT, F. \& DAVIDSON, L. 2002. Understanding and evaluating qualitative research. Australian and New Zealand Journal of Psychiatry, 36:717732.

FUNK, L., STAJDUHAR. K.I., TOYE, C., AOUN, S., GRANDE, G.E. \& TODD, C.J. 2010. Home-based family caregiving at the end of life: a comprehensive review of published qualitative research (1998-2008). Palliative Medicine, 24(6):94-607.

GOVENDER, S. 2007. Social workers face growing national crisis. The Sunday Times, 28 October 2007:13.

GREENBERG, J. \& BARON, R.A. 2008. Behaviour in organizations $\left(9^{\text {th }}\right.$ ed). New Jersey: Pearson Prentice Hall.

GREEN, R. 2003. Social work in rural areas: a personal and professional challenge. Australian Social Work, 56(3):209-219.

GREEN, R., GREGORY, R. \& MASON, R. 2003. It's no picnic: personal and family safety of rural social workers. Australian Social Work, 56(2):94-106.

HARTLEY, S. \& MUHIT, M. 2003. Using qualitative research methods for disability research in majority world countries. Asia Pacific Disability Rehabilitation Journal, 14(2):103-114.

HENNINK, M., HUTTER, I. \& BAILEY, A. 2011. Qualitative research methods. Los Angeles: Sage Publications.

HOLLOWAY, I. \& WHEELER, S. 1998. Qualitative research for nurses. Cambridge, Mass: Blackwell Science.

KREFTING, L. 1991. Rigor in qualitative research: the assessment of trustworthiness. The American Journal of Occupational Therapy, 45(03):214-222.

KRIEG MAYER, A.G. 2001. Rural social work: The perceptions and experiences of five remote practitioners. Australian Social Work, 54(1):91-102.

KRUGER, J. 2008. Rural recruitment \& retention of social workers: consulting the field. Report on the qualitative consultation phase of a project to assist DSD in developing an index of place where social workers would qualify for a rural allowance. Cape Town: Ukwanda in collaboration with the Centre for Scientific \& Industrial Research Built Environment. 
KVALE, S. 1996. Interviews: an introduction to qualitative research interviewing. Thousand Oaks, California: Sage Publications.

LOHMANN, N. \& LOHMANN, R.A. 2005. Rural social work practice. New York: Columbia University Press.

MACK, N., WOODSONG, C., MacQUEEN, K.M., GUEST, G. \& NAMEY, E. 2005. Qualitative research methods: a data collector's field guide. North Carolina: Family Health International.

MAYER, A.G.K. 2001. Rural social work: the perceptions and experiences of five remote practitioners. Australian Social Work, 54(1):91-102.

MILENA, Z.R., DAINORA, G. \& ALIN, S. 2008. Qualitative research methods: a comparison between focus-group and in-depth interview. Annals of the University of Oradea, Economics Science Series, 17(4):1279-1283.

MOLEFE, S.P. 1996. Rural development in South Africa: implications for social work practice. Journal of Social Development in Africa, 11(2):21-31.

NEUMAN, L.W. 2000. Social research methods: qualitative and quantitative approaches $\left(4^{\text {th }}\right.$ ed). London: Allyn \& Bacon.

NGOMANE, E. 2010. Minister: SA needs to retain social workers. The Citizen, 15 December 2010:4.

OLIPHANT, L. 2009. Social work top priority. The City Press, 22 March 2009:12.

PUGH, R. 2007. Dual relationships: personal and professional boundaries in rural social work. British Journal of Social Work, 37:1405-1423.

RANKIN, P. 1992. Resource development as a priority in rural areas: the role of the social worker. Social Work, 28(3):36-47.

RITCHIE, J. \& LEWIS, J. 2005. Qualitative research practice: a guide for social science students and researchers. London: Sage Publications.

ROSS, R.R. \& ALTMAIER, E.M. 1994. Intervention on occupational stress. London: Sage Publications.

SCHENCK, C.J. 2003. Rural social work in South Africa. Unpublished research report. Pretoria: University of South Africa.

SCHENCK, C.J. 2004. Problems rural social workers experience. Social Work, 40(2):158-171.

SHENTON, A.K. 2004. Strategies for ensuring trustworthiness in qualitative research projects. Education for Information, 22:63-75.

SIDELl, N., BOUGHTON, B., HUlL, P., ERTZ, R., SEELEY, K. \& WIEDER, J. 2006. Country life: joys, challenges and attitudes of rural social workers. Rural Social Work and Community Practice, 10(2):35.

STRUWIG, F.W. \& STEAD, G.B. 2001. Planning, designing and reporting research. Cape Town: Pearson.

TERRE BLANCHE, M., DURRHEIM, K. \& PAINTER, D. 2006. Research in practice: applied methods for the social sciences $\left(7^{\text {th }}\right.$ ed). South Africa: University of Cape Town Press. 
TSHISELA, N. 2010. Social worker crisis looms: shortage of skilled people a worry. The Sowetan, 15 December 2010:4.

TURBETT, C. 2009. Tensions in the delivery of social work services in rural and remote Scotland. British Journal of Social Work, 39:506-521.

UNGAR, M. 2003. Qualitative contributions to resilience research. Qualitative Social Work, 2(1):85-102.

VERSLUIS, J-M. 2005. VF+ vra meer geld vir maatskaplike werkers. Die Volksblad, 21 Maart 2005:7.

WHEELDON, J. \& FAUBERT, J. 2009. Framing experience: concept maps, mind maps, and data collection in Qualitative research. International Journal of Qualitative Methods, 8(3):68-83.

Prof Nicky Alpaslan, Department of Social Work, University of South Africa; Prof Rinie Schenck, Department of Social Work, University of the Western Cape, South Africa. 